\title{
O Brasil e a Espanha na dinâmica das migrações internacionais: um breve panorama da situação dos emigrantes brasileiros na Espanha
}

\author{
Erika Masanet Ripoll
}

\begin{abstract}
Paralelamente à inversão migratória no Brasil durante a década de 80 , quando passou a ser um país de emigração, iniciou-se na Espanha o processo contrário, de país de destino da imigração estrangeira. Em pouco tempo, presenciou-se na Espanha uma importante afluência de imigrantes procedentes de um leque geográfico, cultural e étnico cada vez mais amplo, de tal modo que este país tem se convertido, na atualidade, num dos principais destinos dos estrangeiros não comunitários que querem se estabelecer na Europa. O presente trabalho tem como principal objetivo oferecer um panorama sobre a realidade social do coletivo de imigrantes brasileiros estabelecidos na Espanha, a partir de dados secundários procedentes de diversas fontes oficiais espanholas. Assim, é feita uma descrição das características sociodemográficas básicas da população imigrante na Espanha (volume, distribuição geográfica, sexo, idade, etc.), centrando-se no coletivo brasileiro. Da mesma forma, aborda-se o contexto de recepção econômico-laboral da população imigrante na Espanha, visando compreender melhor como se produz a inserção da população imigrante extracomunitária no mercado de trabalho espanhol, e apresentam-se alguns dados socioeconômicos deste segmento e sua comparação com a população brasileira.
\end{abstract}

Palavras-chave: Imigração. Contexto de recepção. Mercado de trabalho.

\section{Introdução}

Sem dúvida, os movimentos de população têm sido uma constante na história da humanidade, como conseqüência de mudanças climáticas, crescimentos demográficos ou necessidades econômicas. Porém, na atualidade, os fluxos migratórios adquirem especial relevância devido ao alcance global dos mesmos. Assim, todos os países vêem-se afetados, de um modo ou de outro, pelas correntes migratórias internacionais: todos são países de origem, de trânsito ou de destino de migrantes, ou então as duas ou as três situações a um só tempo (OIM, 2003).
Neste sentido, o Brasil e a Espanha vêm se inserindo no cenário mundial das migrações internacionais atuais, desempenhando cada qual um papel migratório diferente e invertido durante a década de 80: o Brasil como país de emigração e a Espanha de imigração. Assim, a Espanha tem se convertido num dos destinos da emigração brasileira, embora não seja um dos principais.

Este artigo procura oferecer uma visão sobre a realidade social do coletivo de imigrantes brasileiros estabelecidos na Espanha, a partir de dados secundários procedentes de diversas fontes oficiais espanholas.

\footnotetext{
* Doutoranda em Sociologia no Departamento de Sociologia II da Universidade de Alicante (Espanha).
} 
O texto está estruturado em quatro partes. As duas primeiras, de caráter introdutório e de contextualização do trabalho, abordam as principais características das migrações internacionais - tanto no passado como no presente - e seus paralelismos, bem como a inversão dos fluxos migratórios na Espanha e no Brasil, respectivamente. A seguir, é feita uma descrição das características sociodemográficas básicas da população imigrante na Espanha (volume, distribuição geográfica, sexo, idade. etc.), centrando-se no coletivo brasileiro. Finalmente, analisa-se o contexto de recepção econômico-laboral da população imigrante na Espanha, com o objetivo de compreender melhor como se produz a inserção da população imigrante extracomunitária no mercado de trabalho espanhol, ao mesmo tempo em que são apresentados alguns dados socioeconômicos desta população e sua comparação com a brasileira.

\section{Passado e presente das migrações internacionais: caracterização e paralelismos entre as duas grandes correntes migratórias}

As migrações internacionais constituem um dos elementos do atual processo de globalização. Como aponta S. Castles (2000, p. 17), as migrações recentes decorrem dos processos de internacionalização e interdependência econômica provocados pela globalização.

Neste sentido, J. A. Alonso (2004) sustenta a tese da relação existente entre o grau de abertura das transações econômicas e a intensidade dos fluxos migratórios, mostrando que as duas etapas históricas de maior interdependência econômica - os chamados períodos globalizadores - coincidem com uma maior intensidade das correntes migratórias. ${ }^{1}$

Portes e Rumbaut (1990, p. 8) analisam as diferenças e semelhanças entre as migrações de começo do século $\mathrm{XX}$ : os chamados "velhos migrantes" e os "novos migrantes". A migração para áreas urbanas, sua concentração em algumas cidades portuárias e sua capacidade de aceitar os serviços menos remunerados seriam as semelhanças. Já as diferenças encontramse na composição étnica destes fluxos: se os "velhos migrantes" eram, na maioria, europeus e brancos, a diversificação seria a característica distintiva destes "novos migrantes", procedentes de vários países (majoritariamente daqueles do Terceiro Mundo) e apresentando composições etárias, étnicas e de gênero muito amplas.

A diversificação dos fluxos migratórios internacionais, portanto, seria uma das características das migrações internacionais recentes. Outro aspecto distintivo destes fluxos recentes e que adquire cada vez mais interesse entre os estudiosos sociais das migrações é o surgimento do campo transnacional ou as migrações transnacionais.

A teorização do transnacionalismo foi auspiciada por Schiller, Basch e BlancSzaton (1992), a partir das observações de campo nos fluxos procedentes de Filipinas e Haiti, que tinham como destino a cidade de Nova York. Neste trabalho, os autores observam como os migrantes mantêm vínculos econômicos, sociais e políticos com seus países de origem na sociedade receptora. O processo de globalização, acompanhado dos avanços tecnológicos e das comunicações que encurtam as distâncias e aproximam as pessoas, permite o desenvolvimento de espaços transnacionais que transpassam as fronteiras geográficas, culturais e políticas. Nestes espaços, os migrantes mantêm unidas as sociedades de origem e de recepção, por meio de múltiplas relações - familiares, econômicas, sociais, religiosas, organizacionais ou políticas - entre os dois lugares. ${ }^{2}$ Neste contexto, os migrantes desenvolvem subjetividades e identidades complexas que os vinculam simultaneamente com mais de

\footnotetext{
${ }^{1}$ A primeira grande corrente migratória é aquela formada pelas migrações que se produziram entre o final do século XIX e começo do XX, do velho continente em direção ao novo continente, e a segunda grande onda migratória é a constituída pelas migrações recentes, que começaram por volta de 1970.

2 Os migrantes que desenvolvem e mantêm estas múltiplas relações são denominados "transmigrantes".
} 
um Estado (BASCH, SCHILLER; BLANCSZATON, 1994).

Portanto, a adoção do enfoque do transnacionalismo permite ir além do que acontece na sociedade receptora e obter uma melhor interpretação e compreensão das migrações na atualidade, ao estudar os vínculos existentes entre as sociedades de origem e de destino. Esta série de vínculos, possibilitada pelos meios de comunicação e de informação, traça um marco diferente das migrações no passado.

O economista espanhol José Antonio Alonso também oferece reflexões sobre as similitudes e divergências entre as duas grandes correntes migratórias. Concretamente, questiona-se se as migrações na atualidade constituem uma tendência nova ou se, pelo contrário, compreendem um fenômeno que, com suas especificidades, tem caracterizado outras épocas na história. Como já mencionado, a intensidade dos fluxos migratórios caracterizaria estas duas grandes correntes migratórias produzidas em momentos distintos. Segundo Alonso (2004, p. 11-12), em etapas anteriores à economia mundial, verificaram-se processos migratórios de igual ou maior intensidade aos que ocorrem atualmente. Para o autor, as diferenças entre as duas ondas migratórias radicam em dois elementos. Em primeiro lugar, e coincidindo com a análise de Portes e Rumbaut (1990), alteraramse a composição e a origem da corrente migratória:

[...] en el pasado se trataba de una población cultural y étnicamente semejante a la dominante en el país de acogida y procedente de economías de similar nivel de desarrollo; en la actualidad las corrientes migratorias tiene una más clara dirección Sur-Norte entre países de diferente nivel de desarrollo $y$, en ocasiones incorporando un factor de diversidad étnica o cultural que hace más complejo el proceso de integración en la sociedad receptora (Alonso, 2004, p. 11-12).

Em segundo lugar, um dos elementos que mais distingue as duas etapas migratórias consideradas é o fator da liberdade de movimento. Ou seja, na grande onda migratória do passado existia uma maior liberalidade reguladora dos países receptores, de tal modo que alguns países até possuíam normas favoráveis para incentivar a chegada de imigrantes estrangeiros ao país (ALONSO, 2004, p. 11). É o caso do Brasil, onde havia uma alta e constante demanda de mão-de-obra estrangeira devido ao crescente cultivo de café. Os Estados brasileiros interessados nessa mão-deobra incentivaram a chegada de imigrantes europeus através de subsídios financeiros e de propaganda oficial.

Já no que se refere às migrações internacionais recentes, observa-se um aumento nas políticas restritivas de admissão de estrangeiros nos países receptores, o que tem provocado um incremento nas correntes ilegais e no tráfico clandestino de pessoas. Porém, o endurecimento dos controles fronteiriços não tem impedido a entrada de fluxos migratórios não desejados nos países de imigração. Tal como sustenta Stephen Castles (2000, p. 29), a dificuldade para conseguir um controle eficaz reside em que "en una economía cada vez más internacional, es difícil abrir las fronteras a la circulación de información, bienes y capital si al mismo tiempo se cierran a la circulación de las personas".

\section{A inserção do Brasil e da Espanha no contexto das migrações internacionais recentes: a inversão dos fluxos migratórios nos dois países}

Historicamente, a constituição de muitos países como Estado-Nação e a configuração da sua própria identidade têm sido resultado do movimento internacional de diferentes povos. É o caso do Brasil, onde, desde seu descobrimento, a migração internacional tem desempenhado papel decisivo na formação e composição da sua população, do ponto de vista tanto étnico, cultural e social quanto econômico. Este cenário migratório inverte-se na década de 80, quando o Brasil, que tradicionalmente tinha sido um país de imigração, passou a se converter numa nação de emigração.

A partir dos dados disponíveis sobre a emigração brasileira recente, observa-se, nos últimos anos, uma evolução crescente na saída de brasileiros que migram para outros países em busca de melhores condições de 
vida ou ascensão social. Os dados estimados pelo Ministério das Relações Exteriores do Brasil mostram que, em 2000, havia quase 2 milhões de brasileiros residindo no exterior, ou seja, um pouco mais de $1 \%$ da sua população, sendo que os principais destinos dessa emigração são Estados Unidos, Paraguai, Europa e Japão. Entre os países europeus, a migração brasileira concentra-se, principalmente, na Alemanha, Portugal e Itália, mas também observam-se fluxos importantes para Suíça, França, Inglaterra e Espanha, ocupando este último país o décimo quarto lugar na emigração brasileira no mundo.

Assim, enquanto o Brasil se inseria na dinâmica das migrações internacionais na década de 80 como país de emigração, na Espanha começava o processo contrário. Este país tem uma longa tradição como emissor de emigrantes. Entre a segunda metade do século XIX e começo do XX, uma população nada desprezível de espanhóis emigrou para a América Latina (sobretudo para Argentina, Cuba, Brasil, Uruguai e México), sendo o Brasil o terceiro país escolhido pelos emigrantes espanhóis. Posteriormente, durante as décadas de 50 e 60, o fluxo migratório espanhol dirigiu-se principalmente para a Europa Central, onde havia uma forte demanda de mão-de-obra pouco qualificada para a indústria.

Este panorama migratório alterou-se completamente a partir de meados dos anos 80, quando a Espanha começou a receber imigração estrangeira, devido à sua adesão à Comunidade Econômica Européia (CEE) em 1986. Trata-se essencialmente de imigração econômica procedente do Marrocos, Portugal, Senegal, Guiné Equatorial e América Latina, que conflui com a chegada precedente (e continuada) de estrangeiros da União Européia (majoritariamente aposentados), que procuram a bondade do clima no litoral Mediterrâneo espanhol. $\mathrm{Na}$ década de 90, assistiu-se a uma importante afluência de imigrantes procedentes da África, América Latina e Leste da Europa, resultando numa crescente diversificação nacional e étnica dos fluxos migratórios estabelecidos na Espanha.

Deste modo, a Espanha consolidouse, no final dos anos 90, como país de imigração, convertendo-se num espaço multicultural e pluriétnico, com implicações de diversas naturezas (econômicas, sociais, políticas e culturais).

\section{Características sociodemográficas da população imigrante e brasileira na Espanha}

Os dados indicam que o fenômeno da imigração constitui uma mudança social de grande magnitude, ocorrida na sociedade espanhola em pouco tempo. Isto é evidenciado pelo fato de que a população estrangeira cadastrada ascendeu, de 1996 a 2005, em três milhões de pessoas. Esta evolução crescente da população estrangeira na Espanha acentuou-se, sobretudo, a partir de 2001, sendo que o aumento mais significativo de estrangeiros no país ocorreu entre 2001 e 2003. Segundo os dados referentes a 1 o de janeiro de 2005 , os estrangeiros cadastrados correspondiam a cerca de 3,5 milhões de pessoas, o que equivale a $9 \%$ do total da população espanhola, contra $7 \%$ do ano anterior (INE, 2005).

Segundo dados da Oficina Européia de Estatísticas (Eurostat), ${ }^{3}$ a Espanha foi o país da União Européia que mais imigrantes recebeu durante 2005. O Eurostat estima que 652.300 imigrantes chegaram esse ano na Espanha. Este fluxo de estrangeiros foi o responsável pela maior parte do incremento da população espanhola, o terceiro mais significativo dos membros da UE. Ainda de acordo com as informações do Eurostat, a União Européia teve um acréscimo de dois milhões de habitantes, em 2005, a maioria imigrantes, sendo que a metade dividiuse entre a Espanha (652.300) e a Itália (338.100). ${ }^{4}$ De fato, a Espanha, a Itália, o Reino Unido e a Alemanha receberam 76\% os imigrantes na Europa, em 2005. A partir

\footnotetext{
3 Informação extraída de El País, 28/01/05. Disponível em: <http://www.elpais.es>.

${ }^{4}$ Porém, o Eurostat assinala que estes dados correspondentes aos dois países poderiam estar sobreestimados por causa dos processos de regularização que poderiam ter contabilizado imigrantes que chegaram em anos anteriores.
} 
desses dados, é possível constatar que a Espanha passou a se converter num dos principais destinos dos estrangeiros não comunitários que querem se instalar na Europa.

Sem dúvida, a transformação mais significativa nos últimos anos tem sido protagonizada pela mudança na procedência da população estrangeira: se na atualidade a maioria dos imigrantes provém de países extracomunitários, alguns anos atrás este grupo era formado pelos estrangeiros da União Européia. Apesar da diminuição deste coletivo, a participação da população estrangeira comunitária continua sendo importante no país, com $21 \%$ do total de imigrantes.

No início de 2005, os continentes americano e europeu aglutinavam a maior porcentagem de estrangeiros (ambos somavam $76 \%$ do total de população imigrante). Destacam-se, sobretudo, os procedentes de América do Sul (35\%), configurando-se assim como o coletivo de estrangeiros mais importante no país (INE, 2005).

Quanto à nacionalidade dos imigrantes residentes na Espanha, a população marroquina ocupa o primeiro lugar, representando $14 \%$ do total, seguida pela equatoriana (13\%). ${ }^{5}$ Em terceiro lugar estão os romenos, com $9 \%$ e, a seguir, os colombianos $(7 \%)$, britânicos (6\%), argentinos (4\%) e alemães (4\%) (Tabela 1).

Como se pode observar na Tabela 1, os imigrantes brasileiros não constituem um grupo numericamente importante na Espanha, correspondendo a 54.115 pessoas, em $1^{\circ}$ de janeiro de 2005 . Esta cifra não é muito significativa, quando comparada aos fluxos de imigrantes mais numerosos procedentes da América Latina (equatorianos, colombianos e argentinos). O Brasil situa-se no sétimo lugar entre o conjunto de países latino-americanos, ficando atrás do Equador, Colômbia, Argentina, Bolívia, Peru e República Dominicana.

TABELA 1

População imigrante, segundo principais países de origem

Espanha - 2004-2005

\begin{tabular}{|c|c|c|c|c|c|}
\hline \multirow[b]{2}{*}{ Países de origem } & \multicolumn{2}{|c|}{$2004(1)$} & \multicolumn{2}{|c|}{$2005(1)$} & \multirow[b]{2}{*}{$\begin{array}{l}\text { Variação } \\
\text { relativa (\%) }\end{array}$} \\
\hline & Imigrantes & $\begin{array}{c}\text { Participação } \\
\text { no total de } \\
\text { estrangeiros (\%) }\end{array}$ & Imigrantes & $\begin{array}{c}\text { Participação } \\
\text { no total de } \\
\text { estrangeiros (\%) }\end{array}$ & \\
\hline Marrocos & 420.556 & 13,86 & 511.294 & 13,71 & 21,58 \\
\hline Equador & 475.698 & 15,68 & 497.799 & 13,34 & 4,65 \\
\hline Romênia & 207.960 & 6,85 & 317.366 & 8,51 & 52,61 \\
\hline Colômbia & 248.894 & 8,20 & 271.239 & 7,27 & 8,98 \\
\hline Reino Unido & 174.810 & 5,76 & 227.187 & 6,09 & 29,96 \\
\hline Argentina & 130.851 & 4,31 & 152.975 & 4,10 & 16,91 \\
\hline Alemanha & 117.250 & 3,86 & 133.588 & 3,58 & 13,93 \\
\hline Bolívia & 52.345 & 1,73 & 97.947 & 2,63 & 87,12 \\
\hline Itália & 77.130 & 2,54 & 95.377 & 2,56 & 23,66 \\
\hline Bulgária & 69.854 & 2,30 & 93.037 & 2,49 & 33,19 \\
\hline China & 62.498 & 2,06 & 87.731 & 2,35 & 40,37 \\
\hline Peru & 68.646 & 2,26 & 85.029 & 2,28 & 23,87 \\
\hline França & 66.858 & 2,20 & 77.791 & 2,09 & 16,35 \\
\hline Portugal & 55.769 & 1,84 & 66.236 & 1,78 & 18,77 \\
\hline Ucrânia & 52.748 & 1,74 & 65.667 & 1,76 & 24,49 \\
\hline República Dominicana & 47.973 & 1,58 & 57.134 & 1,53 & 19,10 \\
\hline Brasil & 37.448 & 1,23 & 54.115 & 1,45 & 44,51 \\
\hline Venezuela & 38.718 & 1,28 & 49.206 & 1,32 & 27,09 \\
\hline Argélia & 39.425 & 1,30 & 46.278 & 1,24 & 17,38 \\
\hline Cuba & 39.674 & 1,31 & 45.009 & 1,21 & 13,45 \\
\hline Total Espanha & 3.034 .326 & 100 & 3.730 .610 & 100 & 22,95 \\
\hline
\end{tabular}

Fonte: Instituto Nacional de Estadística - INE. Padrão Municipal de Habitantes, 2004 e 2005.

(1) Refere-se a 10 de janeiro.

5 Em 2003 e 2004, os equatorianos constituíam a principal nacionalidade de estrangeiros no país. 
Porém, quando se consideram os incrementos relativos, verifica-se como os brasileiros experimentaram um aumento notável durante 2004 (em torno a 45\%), constituindo o terceiro coletivo de imigrantes com maior crescimento relativo naquele ano, depois do boliviano (com aumento de mais de $85 \%$ ) e do romeno (que supera $50 \%$ ). Da mesma forma, a evolução do segmento brasileiro na Espanha indica que a expansão mais significativa ocorreu durante 2001 e 2005 (53,50\% e 44,51\%, respectivamente), ${ }^{6}$ o que corrobora a importância que tem adquirido a imigração brasileira na Espanha nos últimos anos.

Destaca-se também a distribuição desigual da população estrangeira no Estado espanhol (Tabela 2), concentrando-se principalmente na Catalunha (21\%), Comunidade de Madri (21\%), Comunidade Valenciana (16\%) e Andaluzia (11\%).

A oportunidade de conseguir uma atividade econômica em Madri e Catalunha, mais concretamente nas cidades de Madri e Barcelona, é o elemento explicativo da presença significativa de imigrantes nestas duas Comunidades Autônomas. No caso da Comunidade Valenciana e Andaluzia, onde reside um segmento importante de estrangeiros comunitários, o fator de atração é o clima e as praias da região, mas também tem influência a possibilidade de se obter "emprego", uma vez que nestas áreas turísticas os residentes comunitários produzem uma maior demanda de serviços, o que permite aos estrangeiros extracomunitários encontrar trabalho (AGUINAGA, 1999, p. 562). Além destas razões, a política de contingentes e as próprias peculiaridades do coletivo também são fatores que explicam esta concentração territorial (CRIADO, 2001, p. 55).

Os dados confirmam, portanto, que a costa mediterrânea (a Catalunha, a Comunidade Valenciana e parte da Andaluzia) e a Comunidade de Madri apresentam maior concentração de população estrangeira, enquanto as Comunidades Autônomas do interior e do norte, em geral, atraem menor proporção de imigrantes.

Esta concentração em determinadas Comunidades Autônomas espanholas também ocorre no caso dos imigrantes brasileiros. Porém, um traço distintivo observado na distribuição da população brasileira é sua maior proporção em algumas comunidades do norte e do interior do país (Galícia, Astúrias, Extremadura e País Basco), em comparação com a população estrangeira em geral. No caso da Galícia, os vínculos históricos poderiam explicar a escolha desta região como destino da migração brasileira. ${ }^{7} \mathrm{Da}$ mesma forma, o fator lingüístico (o galego-português como língua co-oficial da Galícia) também poderia ser outro fator de atração para esta Comunidade Autônoma.

Quanto à variável idade, os imigrantes brasileiros estabelecidos na Espanha formam um grupo, fundamentalmente, jovem e em idade laboral. Com base nos dados do Padrão Municipal de Habitantes de 2005 do INE, os adultos jovens ( 25 a 34 anos) constituem o contingente mais numeroso, representando $39 \%$ dos brasileiros cadastrados no país. Em seguida vêm o grupo de 35 a 44 anos, com $20 \%$, e o segmento juvenil (entre 15 e 24 anos), com 19\% do total de brasileiros.

A respeito da distribuição por sexo da população estrangeira em geral, os dados indicam um leve predomínio da imigração masculina sobre a feminina ( $53 \%$ e $47 \%$, respectivamente). Esta tendência é verificada para a maior parte dos coletivos de imigrantes, com exceção das nacionalidades americanas, em que existe uma clara feminização da migração (54\% de mulheres e $46 \%$ de homens), sendo mais acentuada esta diferença no caso do segmento procedente da América Latina (INE, 2005).

Este predomínio feminino pode estar relacionado às condições do mercado de

\footnotetext{
6 Dados do Padrão Municipal de Habitantes desde 1998 até 2005, Instituto Nacional de Estatística da Espanha (INE)

7 Os imigrantes espanhóis que chegaram ao Brasil entre final do século XIX e começo do XX procediam majoritariamente das regiões da Galícia e Andaluzia.
} 
TABELA 2

Distribuição da população estrangeira e brasileira cadastrada, segundo Comunidades Autônomas Espanha - 2005

\begin{tabular}{|c|c|c|c|c|c|}
\hline \multirow{2}{*}{$\begin{array}{l}\text { Comunidades } \\
\text { Autônomas }\end{array}$} & \multicolumn{2}{|c|}{ População estrangeira } & \multicolumn{2}{|c|}{ População brasileira } & \multirow{2}{*}{$\begin{array}{c}\text { População brasileira } \\
\text { em relação à } \\
\text { estrangeira (\%) }\end{array}$} \\
\hline & $\begin{array}{l}\text { Números } \\
\text { absolutos }\end{array}$ & $\%$ & $\begin{array}{l}\text { Números } \\
\text { absolutos }\end{array}$ & $\%$ & \\
\hline Andaluzia & 420.207 & 11,26 & 5.016 & 9,27 & 1,19 \\
\hline Aragon & 96.848 & 2,60 & 1.408 & 2,60 & 1,45 \\
\hline Astúrias & 26.797 & 0,72 & 1.388 & 2,57 & 5,18 \\
\hline Baleares & 156.270 & 4,19 & 1.886 & 3,49 & 1,21 \\
\hline Canárias & 222.260 & 5,96 & 1.925 & 3,56 & 0,87 \\
\hline Cantábria & 20.547 & 0,55 & 693 & 1,28 & 3,37 \\
\hline Castilha-La Mancha & 115.223 & 3,09 & 804 & 1,49 & 0,70 \\
\hline Castilha e León & 91.318 & 2,45 & 2.762 & 5,10 & 3,03 \\
\hline Catalunha & 798.904 & 21,42 & 11.735 & 21,69 & 1,47 \\
\hline Comunidade Valenciana & 581.985 & 15,60 & 5.291 & 9,78 & 0,91 \\
\hline Extremadura & 25.341 & 0,68 & 1.096 & 2,03 & 4,33 \\
\hline Galícia & 69.363 & 1,86 & 4.662 & 8,62 & 6,72 \\
\hline Madri & 780.752 & 20,93 & 10.172 & 18,80 & 1,30 \\
\hline Múrcia & 165.016 & 4,42 & 954 & 1,76 & 0,58 \\
\hline Navarra & 49.882 & 1,34 & 883 & 1,63 & 1,78 \\
\hline País Basco & 72.894 & 1,95 & 3.047 & 5,63 & 4,18 \\
\hline Rioja (La) & 31.075 & 0,83 & 392 & 0,72 & 1,26 \\
\hline Ceuta & 3.037 & 0,08 & 0 & 0,00 & 0,00 \\
\hline Melilla & 2.891 & 0,08 & 1 & 0,00 & 0,04 \\
\hline Total & 3.730 .610 & 100,0 & 54.115 & 100,0 & 1,45 \\
\hline
\end{tabular}

Fonte: Instituto Nacional de Estadística - INE. Padrão Municipal de Habitantes, 2005.

TABELA 3

Distribuição da população brasileira cadastrada, por sexo

Espanha - 1998-2005

\begin{tabular}{lcc}
\hline Anos & Homens & Mulheres \\
\hline 1998 & 32,17 & 67,83 \\
1999 & 31,39 & 68,62 \\
2000 & 30,85 & 69,15 \\
2001 & 30,79 & 69,22 \\
2002 & 31,48 & 68,52 \\
2003 & 32,78 & 67,22 \\
2004 & 33,74 & 66,26 \\
2005 & 35,96 & 64,04 \\
\hline
\end{tabular}

Fonte: Instituto Nacional de Estadística - INE. Padrão Municipal de Habitantes, Dados revisados 1998 a 2005. Elaboração própria.

trabalho na sociedade de acolhida. Neste sentido, o tipo de demanda de trabalho e a política de contingentes do governo facilitam a feminização crescente da imigração procedente da América Latina, que encontra ocupação principalmente no setor doméstico.

O fluxo migratório brasileiro constitui um dos coletivos de imigrantes mais feminizados na Espanha: $64 \%$ de mulheres e $36 \%$ de homens, segundo dados do Padrão de 2005. Apesar da manutenção deste desequilíbrio de sexos a favor das mulheres nos últimos anos, pode-se verificar o incremento dos homens brasileiros a partir de 2002.

\section{O contexto espanhol de recepção da população imigrante: o mercado de trabalho e as características dos trabalhadores estrangeiros}

Segundo Portes e Rumbaut (1990), os contextos de recepção e os modos de integração da população imigrante definem-se mediante a articulação de três fatores: a política do governo receptor; as condições do mercado de trabalho do organismo receptor; e as características das suas próprias comunidades étnicas. Este artigo se detém no contexto laboral espanhol como um dos fatores determinantes 
na inserção socioeconômica da população imigrante extracomunitária.

Primeiramente, é conveniente realizar uma breve referência ao cenário europeu. A crise do petróleo de 1973 e a conseguinte reestruturação do sistema econômico internacional têm provocado um ponto de inflexão importante a respeito da estrutura do mercado de trabalho dos países europeus, de modo que a precarização do emprego e o desemprego vêm se convertendo em tendências estruturais nestes países.

É neste contexto de reestruturação econômica que têm se produzido os novos movimentos migratórios para a Europa, atingindo cotas importantes durante os anos 80 e 90 e tendo como destino tanto os tradicionais países de imigração (França, Alemanha, etc.), como aqueles de recente imigração (Espanha, Itália e Portugal).

A preocupação em intensificar os controles das fronteiras e a ordenação dos fluxos migratórios à situação do mercado de trabalho seriam os elementos comuns nas políticas de imigração da União Européia (CES, 2004, p. 113). Porém, apesar destas restrições formais que atuam como barreiras, os trabalhadores imigrantes seriam necessários para determinados setores da economia de muitos países europeus, tais como Espanha, Portugal, Grécia e Itália (MALGESINI; JIMÉNEZ, 2000, p. 242).

Nesta linha, cita-se a teoria do mercado dual de Piore (1979), que se centra na sociedade receptora e nos fatores de demanda de trabalho desta. O princípio básico desta teoria é que as migrações internacionais se produzem pela demanda estrutural de mão-de-obra inerente à estrutura econômica das sociedades industriais avançadas. A demanda de imigrantes por parte dos empresários do país receptor explica-se pela existência de um mercado de trabalho dual, que se divide em dois setores: o primário (segurança no emprego, uso intensivo de capital) e o secundário (insegurança laboral, uso intensivo de mão-deobra e baixa produtividade). As economias muito desenvolvidas precisam de pessoal estrangeiro para ocupar trabalhos do setor secundário, rejeitados pelos trabalhadores nativos por suas más condições (empregos precários, mal remunerados, não qualificados, instáveis e de pouco prestígio). Os trabalhadores estrangeiros procedentes de países pobres estão dispostos a aceitar essas ocupações porque os salários, quando comparados àqueles de seus países, são altos e o prestígio que levam em conta é o de seu país de origem.

Atualmente e apesar das similitudes resenhadas, na União Européia coexistem dois modelos de gestão de fluxos migratórios que guardam relação com a importância dos diferentes setores e atividades existentes em cada país. Deste modo, em alguns países do centro e do norte da Europa, os chamados países históricos de imigração, estão sendo adotadas políticas seletivas de imigração, que requerem estrangeiros com alta qualificação no âmbito das Tecnologias da Informação e Comunicação (TIC), investigação e saúde pública. Porém, nos países do sul da Europa, sobretudo Espanha, Portugal e Grécia, onde existem elevado nível de desemprego, forte presença dos setores primário e terciário e fraca situação do I+D+I, a demanda continua se orientando para os empregos que não exigem qualificação específica (CES, 2004, p. 113).

Segundo a classificação do PNUD, com base nos valores do IDH (Índice de Desenvolvimento Humano), a Espanha é considerada um país de alto desenvolvimento humano. Com um valor do IDH em 2003 de 0,928, ocupa a 21a posição entre os países, segundo o último Informe sobre Desenvolvimento Humano (PNUD, 2005). A Espanha mantém esta colocação desde 1997, situando-se num nível superior durante os anos anteriores (em 1995 ocupava o décimo primeiro lugar dos países com maior qualidade de vida).

De acordo com o Informe para o Desenvolvimento Humano (2005), ${ }^{8}$ a esperança de vida ao nascer dos espanhóis é alta: 79,5 anos, sendo 83,2 para as mulheres e 75,9

8 Dados referentes a 2003. 
para os homens. Os índices de educação são elevados (a taxa de alfabetização de adultos é de $97,7 \%$ e a taxa de escolarização bruta combinada dos ensinos fundamental, médio e superior é de $94 \%$ ) e o acesso à saúde é universal. Estes aspectos sociais do bem-estar humano conformariam os elementos favoráveis do contexto espanhol.

Da mesma forma, a economia espanhola vem experimentando há mais de uma década uma importante expansão, de modo que o crescimento econômico na Espanha tem se mantido nos últimos anos um pouco acima da média comunitária. Segundo o Banco da Espanha, o Produto Interior Bruto (PIB) espanhol cresceu 3,4\% em 2005, três décimos mais do que em 2004, e a criação de emprego aumentou $3 \%$, mais quatro décimos.

Apesar dos bons indicadores econômicos (inversão, criação de emprego, inflação, etc.), os principais obstáculos na Espanha continuam sendo o desemprego e a alta taxa de temporalidade no trabalho. Poucos anos atrás, a Espanha possuía uma das taxas de desemprego mais elevadas da União Européia, chegando a 21,60\%, em 1996, um nível inadmissível que, felizmente, tem seguido uma evolução decrescente desde então. Segundo a Enquisa de População Ativa (EPA), do INE, a taxa de desemprego em 2000 era de $13,42 \%$ e tem passado a se situar em $8,70 \%$ da população ativa (1.841.300 de desempregados) durante 2005. Evolução, portanto, bastante positiva do desemprego devido, sobretudo, ao ritmo de crescimento do emprego. Assim, segundo dados do Banco da Espanha, a taxa atual de desemprego vai se aproximando da média comunitária $(7,6 \%)$, além de apresentar um menor desemprego que os dois grandes motores da economia européia: Alemanha $(9,1 \%)$ e França $(9,3 \%)$.

Do mesmo modo, nos últimos anos, tem ocorrido na Espanha um importante crescimento na geração de empregos. Porém, a maioria das ocupações criadas caracterizase por sua precariedade e instabilidade. A taxa de temporalidade chegou a $33,77 \%$ dos assalariados, no quarto trimestre de 2005, sendo que, nos últimos anos, esta taxa tem se mantido estável, não se situando em patamar inferior a $33 \%$. Os jovens e as mulheres são os segmentos mais afetados pelo desemprego e a precariedade laboral. Em 2005, a taxa de desemprego masculina correspondia a $6,64 \%$ e a feminina equivalia a 11,61\% (EPA, 2005).

Desta maneira, observa-se, na Espanha, uma rápida precarização do emprego, bem como a expansão da economia informal, que se concentra em setores produtivos concretos e em certas áreas geográficas. Neste contexto de precarização e instabilidade do mercado de trabalho, se produz a inserção da população imigrante na Espanha nos estratos mais baixos e desvalorizados da estrutura ocupacional, processo que Carlota Solé (1995) denomina de "etnoestratificação" do mercado de trabalho, ou seja, a inclusão dos imigrantes em determinados setores de atividade que conformam o mercado de trabalho secundário, caracterizado por ocupações precárias, que não requerem qualificação e nem especialização profissional, constituindo-se em atividades intensivas em mão-de-obra.

O marco institucional também favorece a reclusão dos trabalhadores estrangeiros em determinados setores de atividade, sendo formado, basicamente, por dois elementos: a normativa de trabalho espanhola, que inclui uma cláusula de prioridade para os trabalhadores nacionais, de modo que a população imigrante somente pode trabalhar nos setores em que a mão-deobra local é insuficiente ("situação nacional do emprego"), e a política de recrutamento de mão-de-obra, segundo "contingentes" fixados pelo governo (PARELLA, 2000, p. 285).

Além disso, destaca-se a importante presença de imigrantes na economia informal no país. Segundo Malgesini e Jiménez (2000, p. 242), a crescente imigração em condições irregulares para a Europa, particularmente para a Europa meridional, guarda estreita relação com o peso da economia informal.

Neste ponto, surge o questionamento a respeito da estranha coexistência de uma alta taxa de desemprego no país e uma importante mão-de-obra estrangeira trabalhando nele. A explicação baseia-se 
em observações empíricas conhecidas. Assim, o motivo principal desta coexistência está na recusa, por parte dos trabalhadores espanhóis, de desempenhar certos tipos de trabalho mal remunerados, não qualificados, perigosos e de pouco prestígio. Estas atividades, que pertencem majoritariamente aos setores da construção, hotelaria, agricultura ou serviço doméstico, passam a ser realizadas pela população imigrante.

A seguir, apresentam-se alguns dados sobre as características socioeconômicas da população imigrante no mercado de trabalho espanhol. Segundo a Enquisa de População Ativa, do INE, em 2005, a taxa de atividade espanhola era de $56,12 \%$, enquanto a dos estrangeiros residentes na Espanha alcançava $73,8 \%$. Esta significativa diferença entre as duas taxas deve-se à estrutura da população imigrante, que se concentra nos grupos em idade de trabalhar. Já a taxa de desemprego dos estrangeiros (10,23\%) é superior à dos espanhóis (8,5\%) .

$\mathrm{Na}$ evolução crescente do número de estrangeiros registrados na Segurança Social nos últimos anos, que passaram de 402.711 para 1.588.215, entre 2000 e 2005 (12 de julho), confirma-se a importância do emprego estrangeiro no mercado de trabaIho espanhol. Este incremento espetacular ocorreu sobretudo em 2005, em virtude do importante processo de regularização de estrangeiros efetuado em maio desse ano, que resultou num aumento de mais de $50 \%$ no número de estrangeiros registrados na Segurança Social, em relação ao ano anterior, um crescimento sem precedentes.

Os trabalhadores estrangeiros registrados em 2005 (cerca de 1,5 milhão de pessoas) representam $8 \%$ do total de trabalhadores registrados na Espanha (OPI, 2005). Do total de trabalhadores estrangeiros registrados, 12.405 são brasileiros, sendo 63\% mulheres e $37 \%$ homens. Esta distribuição por sexo assemelha-se à participação de homens e mulheres no conjunto do coletivo brasileiro cadastrado na Espanha, como visto anteriormente. A média de idade dos trabalhadores brasileiros situa-se em torno dos 33 anos (Tabela 4).

Quanto à posição na ocupação, a maioria dos trabalhadores estrangeiros registrados na Segurança Social, incluindose os procedentes da América Latina, é composta por assalariados. Entre o grupo latino-americano, destaca-se que os mexicanos, brasileiros e venezuelanos possuem as maiores proporções de trabalhadores autônomos (14,7\%, 13,7\% e 13,6\%, respectivamente).

Segundo os dados do Informe sobre la migración y el mercado de trabajo en España, do CES (2004), e como já mencionado anteriormente, os setores de atividade econômica com maior concentração de população imigrante são o serviço domés-

TABELA 4

Trabalhadores estrangeiros registrados na Segurança Social, segundo países de origem Espanha - 2005

\begin{tabular}{lccccc}
\hline Países de origem & Assalariados (\%) & Autônomos (\%) & Média de idade & Mulheres (\%) & Total \\
\hline América Latina & $\mathbf{9 0 , 6 5}$ & $\mathbf{9 , 3 5}$ & $\mathbf{3 5}$ & $\mathbf{5 1 , 8 2}$ & $\mathbf{6 2 6 . 4 2 6}$ \\
Equador & 91,93 & 8,07 & 34 & 50,91 & 249.048 \\
Colômbia & 88,71 & 11,29 & 35 & 56,32 & 128.864 \\
Peru & 94,72 & 5,28 & 36 & 49,54 & 59.946 \\
Argentina & 86,66 & 13,34 & 36 & 42,32 & 49.321 \\
Bolívia & 89,15 & 10,85 & 33 & 55,65 & 26.139 \\
Rep. Dominicana & 93,30 & 6,70 & 34 & 62,09 & 25.982 \\
Cuba & 91,35 & 8,65 & 37 & 46,85 & 20.455 \\
Uruguai & 88,74 & 11,26 & 36 & 42,59 & 14.870 \\
Brasil & $\mathbf{8 6 , 3 0}$ & $\mathbf{1 3 , 7 0}$ & $\mathbf{3 3}$ & $\mathbf{6 2 , 5 9}$ & $\mathbf{1 2 . 4 0 5}$ \\
Venezuela & 86,37 & 13,63 & 35 & 53,44 & 12.395 \\
Chile & 90,97 & 9,03 & 37 & 40,53 & 12.308 \\
México & 85,26 & 14,74 & 35 & 51,74 & 4.445 \\
Paraguai & 90,57 & 9,43 & 34 & 64,30 & 3.880 \\
Honduras & 89,42 & 10,58 & 33 & 65,30 & 2.268 \\
Outros da América Latina & 89,46 & 10,54 & 35 & 59,46 & 4.100 \\
Total de estrangeiros & $\mathbf{8 7 , 4 6}$ & $\mathbf{1 2 , 5 4}$ & $\mathbf{3 5}$ & $\mathbf{3 9 , 4 6}$ & $\mathbf{1 . 5 8 8 . 2 1 5}$ \\
\hline
\end{tabular}

Fonte: Observatório Permanente da Imigração (OPI), Ministério de Trabalho e Assuntos Sociais da Espanha. 
tico, a agricultura, a hotelaria e a construção. Destaca-se, também, a grande participação dos imigrantes em outras atividades, de menor importância no volume de emprego total, como a do "comércio não realizado em estabelecimentos".

O sexo dos imigrantes tem influência significativa no setor de atividade de trabalho em que se inserem, de tal forma que se pode falar de uma especialização do trabalho segundo o sexo dos imigrantes ou uma "segregação ocupacional por razões de gênero", conforme as palavras de Sonia Parella (2000). Assim, segundo o Anuário de Estatísticas Laborais 2004, do Ministério de Trabalho e Assuntos Sociais da Espanha, os homens concentram-se principalmente na construção (27\%), agricultura (14\%) e hotelaria $(11 \%),{ }^{9}$ enquanto as mulheres têm maior participação no setor serviços: hotelaria $(21 \%)$ e serviço doméstico $(18 \%) .{ }^{10}$ Neste sentido, é um fato importante a dimensão que tem adquirido, nos últimos anos, o trabalho da mulher imigrante no setor doméstico e pessoal, o que está intrinsecamente relacionado ao envelhecimento da população, à forte incorporação ao mercado de trabalho da mulher espanhola, assim como aos cortes nas ajudas sociais pela crise fiscal do Estado de Bem-Estar nas sociedades ocidentais. Estas mudanças sociodemográficas e econômicas explicariam a crescente feminização dos fluxos migratórios para a Espanha.

Quanto aos contratos de trabalho (Tabela 5), $2 \%$ daqueles subscritos a estrangeiros latino-americanos pertenciam a brasileiros. Destes, $58 \%$ de mulheres e $41 \%$ de homens. Embora esta proporção continue sendo favorável à mulher, observa-se um decréscimo no número de contratos femininos em relação à sua participação no conjunto da população brasileira na Espanha. Este fato está estreitamente vinculado ao tipo de trabalho exercido pelas mulheres imigrantes no país, que é caracterizado pela elevada precariedade no trabalho.

Como se pode observar na Tabela 5, os trabalhadores latino-americanos realizam, em maior medida, trabalhos no setor serviços (65\%) em relação ao total da população estrangeira (55\%), mas desempenham em menor proporção atividades no setor da agricultura $(7 \%$ contra $15 \%$ da população

TABELA 5

Contratos registrados de estrangeiros, por setor de atividade, segundo países de origem Espanha - junho 2005

\begin{tabular}{|c|c|c|c|c|c|c|}
\hline Países de origem & Agricultura (\%) & Indústria (\%) & Construção (\%) & Serviços (\%) & Mulheres (\%) & Total \\
\hline América-Latina & 7,23 & 5,89 & 21,46 & 65,41 & 45,41 & 475.415 \\
\hline Equador & 14,06 & 6,52 & 26,59 & 52,83 & 43,01 & 186.198 \\
\hline Colômbia & 3,45 & 6,10 & 20,34 & 70,10 & 49,36 & 98.354 \\
\hline Peru & 2,42 & 3,78 & 17,67 & 76,14 & 46,07 & 54.090 \\
\hline Argentina & 1,08 & 5,90 & 13,12 & 79,90 & 42,25 & 38.864 \\
\hline Rep. Dominicana & 1,72 & 3,73 & 23,31 & 71,24 & 51,80 & 21.195 \\
\hline Cuba & 1,44 & 5,60 & 13,01 & 79,95 & 47,75 & 17.346 \\
\hline Bolívia & 13,08 & 7,11 & 29,27 & 50,54 & 35,44 & 12.414 \\
\hline Uruguai & 1,34 & 7,04 & 17,00 & 74,64 & 39,93 & 10.472 \\
\hline Chile & 1,65 & 7,05 & 19,04 & 72,26 & 38,64 & 9.725 \\
\hline Brasil & 1,80 & 5,51 & 13,09 & 79,60 & 58,71 & 9.042 \\
\hline Venezuela & 1,29 & 5,25 & 10,87 & 82,59 & 51,02 & 8.626 \\
\hline México & 0,86 & 5,44 & 5,30 & 88,40 & 56,51 & 2.904 \\
\hline Paraguai & 5,90 & 6,06 & 27,51 & 60,53 & 40,88 & 1.781 \\
\hline Honduras & 3,62 & 6,92 & 12,89 & 76,67 & 56,84 & 1.272 \\
\hline Outros da América Latina & 2,81 & 5,04 & 15,36 & 76,79 & 48,60 & 3.132 \\
\hline Total de estrangeiros & 15,46 & 6,21 & 23,24 & 55,10 & 33,09 & 1.219 .673 \\
\hline
\end{tabular}

Fonte: Observatório Permanente da Imigração (OPI), Ministério de Trabalho e Assuntos Sociais da Espanha.

\footnotetext{
9 Segundo o relatório do CES (2004), os homens concentram-se mais no setor primário (agricultura) e sobretudo na construção e menos no setor serviços e na indústria, em comparação com a população trabalhadora nativa.

10 Assinala-se, ainda, que esta última cifra relativa ao serviço doméstico está infravalorada, pois existe um importante número de mulheres irregulares que trabalham sem contrato de trabalho no serviço doméstico e que, portanto, não estão contabilizadas nas estatísticas.
} 
total estrangeira). Quanto aos contratos registrados de trabalhadores brasileiros, a maioria corresponde a empresas do setor de serviços (8 em cada 10), seguidos, à distância, por aqueles referentes a empresas da construção (13\%), da indústria (5\%) e do setor agrícola (2\%). Este coletivo, juntamente com o grupo de mexicanos, venezuelanos, cubanos e argentinos, constitui os trabalhadores latino-americanos com maior participação no setor serviços.

Examinando as porcentagens do grupo brasileiro em relação à média dos trabalhadores latino-americanos e dos estrangeiros em geral, verifica-se como a população brasileira realiza em maior medida trabalhos no setor serviços, ao mesmo tempo em que participa em menor medida nos setores da construção e da agricultura. Evidentemente, a alta incidência do trabalho no setor serviços entre a população trabalhadora brasileira tem sua origem na forte feminização do coletivo.

O processo de "etno-estratificação" do mercado de trabalho espanhol é confirmado com a importante presença de imigrantes em setores de atividades caracterizados por trabalhos precários, que não requerem qualificação e nem especialização profissional, constituindo atividades intensivas em mão-de-obra. A inserção dos imigrantes no mercado de trabalho secundário mostra, portanto, que este segmento é um dos mais vulneráveis e tendentes à exclusão social, no país.

\section{Considerações finais}

O conteúdo exposto ao longo do presente trabalho permite traçar, de maneira geral, alguns paralelismos históricos entre a imigração de massa ocorrida no passado e o processo de emigração recente, no Brasil. Mais concretamente, entre o fluxo migratório espanhol para o Brasil, anteriormente, e o fluxo migratório atual brasileiro que tem como destino a Espanha. Trata-se de dois países com vinculações históricas ligadas às migrações internacionais, o que pode ser observado, por exemplo, na eleição do destino migratório dos brasileiros na Espanha. Assim, em relação à população es- trangeira em geral, a comunidade brasileira na Espanha, proporcionalmente, tem maior presença na Galícia, devido, provavelmente, a seus laços históricos com o Brasil, que remontam às migrações em massa do passado, e ao fator lingüístico.

Quanto aos destinos migratórios, o Brasil foi o terceiro país escolhido pelos emigrantes espanhóis, depois da Argentina e de Cuba. Da mesma forma, a imigração espanhola para o Brasil ocupou o terceiro lugar em importância numérica (depois da italiana e portuguesa) (BASSANEZI, 1996). Porém, na emigração dos brasileiros para o exterior na atualidade, a Espanha não constitui a principal preferência. Assim, os mais importantes destinos dos fluxos brasileiros são os Estados Unidos, Paraguai, Europa e Japão. Entre os países europeus, a emigração brasileira concentra-se, principalmente, na Alemanha, Portugal e Itália. De igual modo e da perspectiva do país de destino, o coletivo imigrante brasileiro assentado na Espanha não constitui um grupo numericamente significativo no país. Estima-se, portanto, uma tendência à maior diversificação dos países de destino na emigração brasileira atual (EUA, Europa e Japão). Já nas migrações de massa do passado, o principal foco de destino dos emigrantes era o continente americano, sendo o Brasil e a Argentina os principais destinos da imigração européia para a América Latina e o Caribe, em fins do século XIX e início do XX.

$\mathrm{Na}$ atualidade, a Espanha consolida-se como país de imigração e passa a se converter num espaço multicultural e pluriétnico, com implicações de diversas naturezas (econômicas, sociais, políticas e culturais). Neste contexto de imigração e de crescente diversificação étnica dos fluxos migratórios, tem lugar a chegada de população brasileira na Espanha. Embora o coletivo imigrante brasileiro não tenha presença significativa na Espanha, a evolução deste segmento é um indicador da importância que tem adquirido a imigração brasileira no país nos últimos anos e que provavelmente continuará crescendo influenciado pelo estabelecimento de redes sociais no país.

O fluxo migratório brasileiro que tem como destino a Espanha apresenta um 
forte desequilíbrio por sexo a favor das mulheres brasileiras, constituindo um dos coletivos de imigrantes mais feminizados na Espanha. Uma das razões disso estaria relacionada ao tipo de demanda de trabalho no país e que tem a ver com as mudanças sociodemográficas e econômicas que têm se produzido na Espanha nas últimas décadas. Em conseqüência à sua elevada feminização, o coletivo brasileiro apresenta alta concentração no setor de serviços, caracterizado pela elevada precariedade

\section{Referências bibliográficas}

ASSIS, G. O. De Criciúma para o mundo - os novos fluxos da população brasileira: gênero e rearranjos familiares. In: MARTES, A. C.; FLEISCHER, S. (Orgs.). Fronteiras cruzadas: etnicidade, gênero e redes sociais. São Paulo: Vozes, 2003, p. 199230.

AGUINAGA, J. Inmigrante o ciudadano. El proceso de integración en la sociedad española. In: TEZANOS, J. F. Tendencias en desigualdad y exclusión social. Madrid: Sistema, 1999, p. 549-581.

ALONSO, J. A. Emigración y desarrollo. Implicaciones económicas. Madrid: La Catarata, 2004.

BASCH, L.; SCHILLER, N.G.; BLANCSZANTON, C. Nations unbound. Transnational projects, postcolonial predicaments and deterritorialized Nations-states. Pensilvania: Gordon and Breach Science Publishers, 1994.

BASSANEZI, M. Imigrações internacionais no Brasil: um panorama histórico. In: PATARRA, N. (Coord.). Emigração e imigração internacionais no Brasil contemporâneo. São Paulo: FNUAP, 1996, p. 1-38.

BÓGUS, M; BASSANEZI, M. Brasileiros na Itália: movimentos migratórios e inserção social. Margem, v.10, p. 211-227, 1999.

CASTLES, S. Migración internacional a comienzos del siglo XXI: tendencias y problemas mundiales. Revista Internacional de Ciencias Sociales, n. 165, p. 17-32, 2000. laboral e alta incidência da situação irregular. A literatura sobre a situação das imigrantes brasileiras em outros países, como os Estados Unidos (ASSIS, 2003; FLEISCHER, 2001; PADILLA, 2001), Itália (BOGUS; BASSANEZI, 1999) e Portugal (DINIZ, 2005; GONÇALVES; FIGUEIREDO, 2005), também aponta esta preeminência da mulher imigrante brasileira no setor serviços, em particular no trabalho doméstico, e sua condição precária e vulnerável no mercado de trabalho.

CONSEJO ECONÓMICO Y SOCIAL - CES. Informe sobre la migración y el mercado de trabajo en España. Madrid, 2004. Disponível em: <http://www.ces.es>.

CRIADO, M. J. La línea quebrada. Historias de vida de migrantes. Madrid: Consejo Económico y Social - CES, 2001.

DINIZ, E. C. A Mulher brasileira na imigração em Portugal. Imigração e etnicidade: vivências e trajectórias de mulheres em Portugal. Lisboa: SOS Racismo, 2005.

FLEISCHER, S. Pensando a identidade brasileira no contexto do "housecleaning" em Bóston, Massachussets. In: CONFERÊNCIA DALATINAMERICANSTUDIESASSOCIATION MEETING. Washington DC, 2001.

GONÇALVES, M.; FIGUEIREDO, A. Mulheres imigrantes em Portugal e o mercado de trabalho: diferentes percursos, inserções laborais semelhantes. Imigração e etnicidade: vivências e trajectórias de mulheres em Portugal. Lisboa: SOS Racismo, 2005.

INSTITUTO NACIONAL DE ESTADÍSTICA - INE. Encuesta población activa (EPA). Madrid, 2005. Disponível em: <http://www. ine.es>. Acesso em: 7 fev. 2006.

Estadísticas. Madrid, 2005. Disponível em: <http://www.ine.es>. Acesso em: 3 fev. 2006.

MALGESINI, G.; JIMÉNEZ, C. Guía de conceptos sobre migraciones, racismo e interculturalidad. Madrid: Los Libros de la Catarata, 2000. 
MINISTERIO DE TRABAJO Y ASUNTOS SOCIALES. Anuario de Estadísticas Laborales y de Asuntos Sociales 2004. Madrid, 2005. Disponível em: <http://www. mtas.es/estadisticas/anuario2004/welcome. htm >. Acesso em: 12 fev. 2006.

MINISTÉRIO DAS RELAÇÕES EXTERIORES - MRE, Brasília, DF. Disponível em: <http:// www. itamaraty.gov.br>.

OBSERVATORIO PERMANENTE DE LA INMIGRACIÓN - OPI. Trabajadores extranjeros en el mercado de trabajo español. Boletín estadístico de extranjería e inmigración, n. 6, 2005. Disponível em: $<$ http://extranjeros.mtas.es $>$. Acesso em: 3 fev. 2006.

ORGANIZACIÓN INTERNACIONAL PARA LA MIGRACIÓN - OIM. Hechos y cifras sobre la migración internacional. Cuestiones de Políticas Migratorias, n. 2, março, 2003.

PADILLA, B. Women's organizing in a global context: activism in Salvador, Brazil, at the crossroad of race, class and gender. Ph.D. Dissertation. University of Illinois at Urbana-Champaign, 2001.

PARELLA, S. El trasvase de desigualdades de clase e etnia entre mujeres: los servicios de proximidad. Papers, n. 60 , p. 275-289, 2000.

PATARRA, N. (Coord.). Emigração e imigração internacionais no Brasil contemporâneo. São Paulo: FNUAP, 1996.

PIORE, M. Birds of passage. Migrant labor and industrial societes. New York: Cambridge University Press, 1979.

PROGRAMA DE NACIONES UNIDAS PARA EL DESARROLLO - PNUD. La cooperación internacional ante una encrucijada: ayuda al desarrollo, comercio y seguridad en un mundo desigual. Informe sobre desarrollo humano 2005. Madrid: Mundi-Prensa, 2005. Disponível em: http:<//www.pnud.org>.

PORTES, A.; RUMBAUT, R. Immigrant America: a portrait. Berkley: University of California Press, 1990.

SCHILLER, N. G.; BASCH, L.; BLANCSZANTON, C. Towards transnational perspective on migration: race class etnhnicity and nationalism reconsidered.

Annals of the New York academy of Sciencies, New York, vol. 645, 1992.

SOLÉ, C. Discriminación racial en el mercado de trabajo. Madrid: Centro de Investigaciones Sociológicas - CIS, 1995.

\section{Resumen}

Brasil y España en la dinámica de las migraciones internacionales: Un breve panorama de la situación de los emigrantes brasileños en España

Paralelamente a la inversión migratoria en Brasil durante la década del 80, cuando pasó a ser un país de emigración, se inició en España el proceso contrario, de país de destino de la inmigración extranjera. En poco tiempo, se presenció en España una importante afluencia de inmigrantes procedentes de un abanico geográfico, cultural y étnico cada vez más amplio, de tal modo que este país se ha convertido en la actualidad, en uno de los principales destinos de los extranjeros no comunitarios que quieren establecerse en Europa. El presente trabajo tiene como principal objetivo ofrecer un panorama sobre la realidad social del colectivo de inmigrantes brasileños establecidos en España, a partir de datos secundarios procedentes de diversas fuentes oficiales españolas. Así, es realizada una descripción de las características socio-demográficas básicas de la población inmigrante en España (volumen, distribución geográfica, sexo, edad, etc.), centrándose en el colectivo brasileño. De la misma forma, se aborda el contexto de recepción económico-laboral de la población inmigrante en España, buscando comprender mejor como se produce la inserción de la población inmigrante extracomunitaria en el mercado laboral español, y se presentan algunos datos socioeconómicos de este segmento y su comparación con la población brasileña.

Palabras-clave: Inmigración. Contexto de recepción. Mercado laboral. 


\begin{abstract}
Brazil and Spain in the dynamics of international migrations: a brief description of the situation of Brazilian immigrants in Spain

Brazil became an emigration country during the 1980s, at a time when Spain was going through a period of greater immigration. Spain was receiving great numbers of immigrants of many different geographic, cultural and ethnic origins. In fact, it is now one of the most important destinations of non-European foreigners who wish to move to the Continent. The aim of this investigation is to offer an approach to the social reality of Brazilian immigrants in Spain, based on secondary data from different official Spanish sources. We describe basic socio-demographic characteristics of the immigrant population in Spain (volume, geographic distribution, gender, age and others), with special focus on Brazilians. We also discuss the context of the economic and professional reception of immigrants in Spain in order to come to a better understanding of the presence of the non-European immigrant population in the Spanish labor market. We also present socioeconomic data regarding this population and compare it with the Brazilian population.
\end{abstract}

Keywords: Immigration. Context of reception. Labor market.

Recebido para publicação em 05/12/2006. Aceito para publicação em 25/04/2008. 